\title{
Hunting a Deer to Extinction
}

\section{lan Grimwood}

Calamian deer, which are found only in the Philippine Islands, have been so reduced in numbers over the last thirty years that unless hunting can be controlled, they are doomed to extinction. This is Ian Grimwood's conclusion after his 1975 survey which was aided by an Oryx $100 \%$ Fund grant. The deer have no enemy but man. There was no hunting during the Japanese occupation, and at the end of the Japanese war numbers were quite high. Since then increased hunting pressure has led to an accelerating decline, with more and more people hunting fewer and fewer deer. Today Ian Grimwood suggests the maximum number cannot be over 900 animals, and is probably much less, and extinction is certain unless action is taken. The following are extracts from the report:

The Calamian deer Axis calamianensis is known only from the Calamian Islands, which lie off the northern tip of Palawan, itself the westernmost island of the Philippines.

The islands contain no large carnivore, consequently man is the deer's only enemy. Somewhat unusually, man's impact on its environment has if anything been beneficial, because forest clearance for settlement has tended to increase the extent of its natural habitat. The deer are doubly protected from hunting, both because no deer species may be hunted without license anywhere in the Philippines and also because the Calamian Islands all lie within the Palawan Game Refuge and Bird Sanctuary, declared in 1967. Their future should, therefore, be assured, but unfortunately the legal protection is meaningless. In practice deer are openly hunted by all the residents of the islands, from the highest to the lowest, at every opportunity, by every possible means, at every season of the year, and without regard to age or sex. It is doubtful if the law is even known to many of the hunters, for no attempt is made to enforce it and it is broken with impunity. No stigma therefore attaches to this illegal hunting; indeed the successful hunter is looked upon with admiration. In consequence the number of deer has been in sharp decline for many years.

Until recently the greatest toll was taken by night hunting with a torch and a shotgun. But in September 1972 the introduction of martial law was followed by the withdrawal of firearms from the public, and the deer got a respite. However, a certain number of rifles of .22 calibre were apparently allowed to be retained and are still used for hunting, and deer are now also hunted with dogs and captured by snares, pitfalls and other methods in such numbers that the decline has continued.

The extreme scarcity of meat and reliance on wild animals for food, of which the deer and the wild boar are both the largest and most palatable, provide the impetus for hunting. Venison commands a ready market, and, because of the difficulty of keeping meat fresh in a hot climate, animals are often transported alive for sale in the nearest centre or settlement, with much resulting suffering and cruelty. Bearing in mind the low level of average income- the salary of a junior clerk in government service is about P300 to $\mathrm{P} 350$ per month (P7 equals US\$1) - the prices that are realised are very high; P7 to P8 being paid per kilo for butchered meat and P5 to P6 per kilo for 


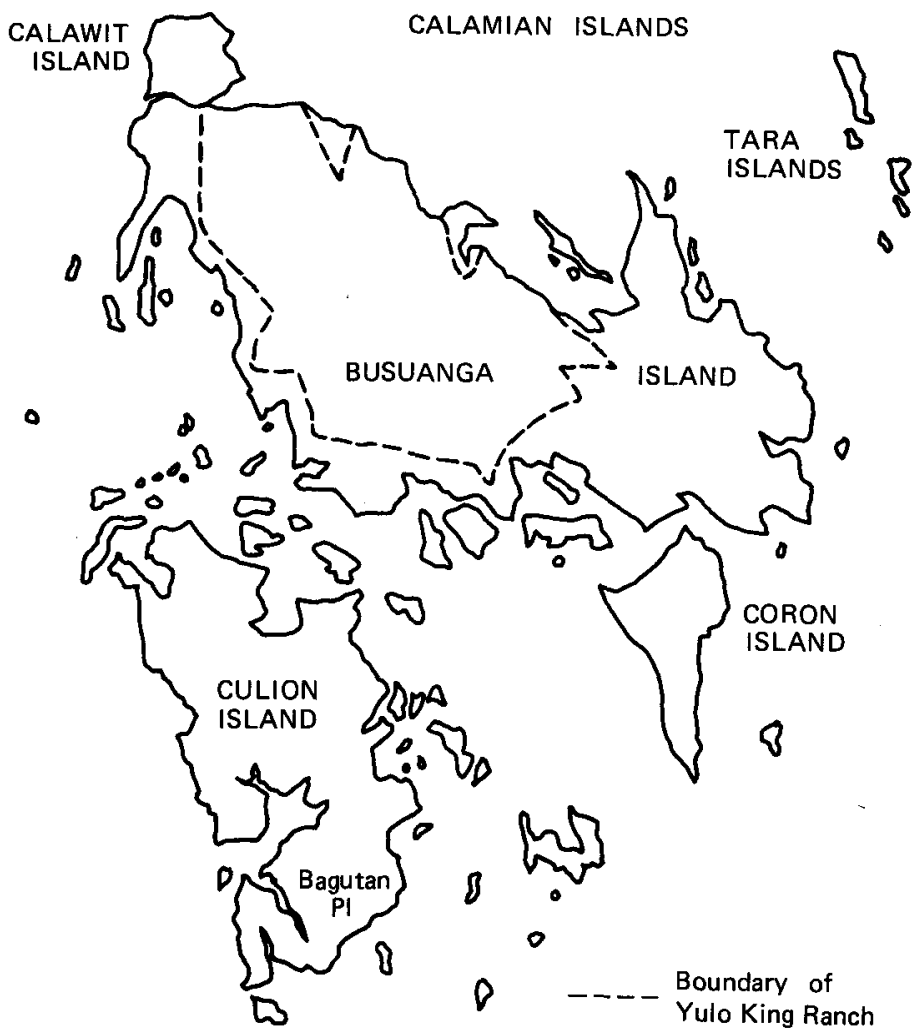

dressed carcases; a live adult male was sold for P220 while the writer was in Busuanga and butchered by the purchaser on the spot.

Thirty years ago deer were to be found in surprisingly large numbers in all suitable localities throughout the islands of Busuanga and Culion, where most of the deer have always occurred. On Busuanga the effects of the heavy hunting that started shortly afterwards soon began to show, both in fewer animals being seen in any one group and in the elimination of one local population after another. By 1972 the hunter/hunted ratio had increased so greatly, and other methods of hunting had become so commonly used, that the withdrawal of firearms was not enough to reverse the trend. The deer continue to decline to this day, albeit at a slower rate, and they are now only found in small, isolated and widely scattered populations.

On Culion the situation is somewhat better. Deer have suffered most in the north where, because of increasing settlement, they are now subject to the same sort of hunting pressure as on Busuanga, but they are believed to be still reasonably widespread in that region, even in the central resettlement area. What are by comparison good stocks still exist around the plains in the more lightly settled southern end of the island, and smaller numbers occur in many areas of thin forest where they have no access to any large open space. But even the remotest plains are regularly visited by hunters, so that even in the south numbers are almost certainly still declining. The same factors are at 
work on Culion as on Busuanga, and Culion must be regarded as being only a few years behind in the process of extermination.

On the smaller islands the current position is discouraging, and it seems unlikely that deer survive on more than a few of them, and then only in very small numbers.

In summary, it appears that the Calamian deer has suffered a great reduction in numbers over the last thirty years and that, although nominally protected, it continues to decline in every part of its limited range. It probably no longer exists in significant numbers other than on the main islands of Busuanga and Culion, where local populations have everywhere reached dangerously low levels, with the possible exception of the extreme south of Culion. The sole cause of its decline is illegal hunting. Unless this can be brought under control, or an effective sanctuary created, the species appears doomed to early extinction.

It was not possible to make any proper estimate of numbers, but an 'informed guess' suggests that the total population could conceivably be as high as 900 ; it is most unlikely to exceed that figure and is almost certainly very much less, probably only half that number.

There seems little hope that the Philippines Government could bring hunting under control in time to save the Calamian deer. So deeply ingrained a habit can probably not be eradicated in less than a decade, and would need an enormous law-enforcement staff. Meanwhile the position will be exacerbated by an inevitable increase in the human, and therefore hunter, population. Designation of the Calamian Islands as a Game Refuge and Bird Sanctuary has merely superimposed a conservation area on a settlement and has proved unworkable. As far as government action is concerned, therefore, the survival of this unique species depends on the establishment of a new and effective reserve or reserves, where all human activities can be excluded and to which entry is strictly controlled. For so sedentary a species such reserves need not be large, and several excellent sites exist in the unsettled parts of south Culion, where an area of forest surrounding one of the plains such as Bagutan could be set aside. It would be of advantage simultaneously to take over one of the smaller islands, to which a viable population could be moved. This would be easier to protect, and one man in a fast boat could prevent any landing.

In the private field the Yulo King Ranch, planned for December 1975 and occupying more than half the island of Busuanga, could play a vital part in the saving of the species because it will contain anything from one quarter to one third of the surviving animals. The deer are unlikely to conflict with ranching interests or procedures in any way, and this 50,000-hectare, settlement-free estate could act as a large privately run reserve.

Postscript: At its meeting in Zaïre last September the Survival Service Commission (SCC) approved John Aspinall's offer to take a small group of Calamian deer for breeding at his wildlife park in Kent. This was approved by both J. B. Alvarez, head of the Philippines Parks Wildlife Office, and Major Grimwood who were present.

Ian Grimwood's report covers the biology and habits of the Calamian deer as well as distribution and status. Copies of the full report are obtainable from the FPS office, price 20p. 